\title{
Variation in human dental pulp stem cell ageing profiles reflect contrasting proliferative and regenerative capabilities
}

\author{
Amr Alraies ${ }^{1,2}$, Nadia Y. A. Alaidaroos ${ }^{2,3}$, Rachel J. Waddington ${ }^{1,2}$, Ryan Moseley ${ }^{2,3}$ and Alastair J. Sloan ${ }^{1,2^{*}}$
}

\begin{abstract}
Background: Dental pulp stem cells (DPSCs) are increasingly being recognized as a viable cell source for regenerative medicine. Although significant variations in their ex vivo expansion are well-established, DPSC proliferative heterogeneity remains poorly understood, despite such characteristics influencing their regenerative and therapeutic potential. This study assessed clonal human DPSC regenerative potential and the impact of cellular senescence on these responses, to better understand DPSC functional behaviour.

Results: All DPSCs were negative for hTERT. Whilst one DPSC population reached $>80$ PDs before senescence, other populations only achieved $<40$ PDs, correlating with DPSCs with high proliferative capacities possessing longer telomeres $(18.9 \mathrm{~kb})$ than less proliferative populations $(5-13 \mathrm{~kb})$. High proliferative capacity DPSCs exhibited prolonged stem cell marker expression, but lacked CD271. Early-onset senescence, stem cell marker loss and positive CD271 expression in DPSCs with low proliferative capacities were associated with impaired osteogenic and chondrogenic differentiation, favouring adipogenesis. DPSCs with high proliferative capacities only demonstrated impaired differentiation following prolonged expansion (>60 PDs).

Conclusions: This study has identified that proliferative and regenerative heterogeneity is related to contrasting telomere lengths and CD271 expression between DPSC populations. These characteristics may ultimately be used to selectively screen and isolate high proliferative capacity/multi-potent DPSCs for regenerative medicine exploitation.
\end{abstract}

Keywords: Dental pulp, Stem cells, Cumulative population doublings, Telomeres, Cellular senescence, Differentiation, Multi-potency, CD271

\section{Background}

Dental pulp stem cells (DPSCs) are increasingly becoming recognized as a viable cell source for the development of effective cell-based therapies. This is due to their accessibility, multi-lineage differentiation capabilities towards osteogenic, chondrogenic, myogenic and neurogenic lineages; and similar regenerative properties to bone marrow-derived cells [1-4]. DPSCs exhibit a fibroblast-like morphology, plastic

\footnotetext{
* Correspondence: Sloanaj@cardiff.ac.uk

${ }^{1}$ Mineralised Tissue Group, Oral and Biomedical Sciences, School of Dentistry, College of Biomedical and Life Sciences, Cardiff University, Heath Park, CF14 4XY, Cardiff, UK

${ }^{2}$ Cardiff Institute Tissue Engineering and Repair (CITER), Cardiff University, Cardiff CF14 4XY, UK

Full list of author information is available at the end of the article
}

adherence, express mesenchymal stem cell (MSC) markers (CD73, CD90 and CD105); and thus satisfy the minimal criteria for MSCs $[1,3,5,6]$. However, similar to bone marrow stem cells, DPSCs isolated from pulpal tissues are recognised to represent a heterogeneous population, with individual isolated clones demonstrating differences in proliferative rates and their abilities to differentiate down particular lineages $[1,5,7]$. Indeed, despite heterogeneous DPSC population expansion being capable of achieving $>120 \mathrm{cu}-$ mulative population doublings (PDs) in vitro, only $20 \%$ of purified DPSCs are capable of proliferating beyond $>20$ PDs. Of these, only two-thirds were able to generate abundant ectopic dentine in vivo, implying that subset DPSC populations differ in their regenerative potential $[5,7]$. In vitro, heterogeneous DPSCs 
can differentiate into osteoblasts, chondrocytes, adipocytes, neurocytes and myocytes, but it has been reported that there are occasions when DPSCs fail to differentiate into adipocytes, chondrocytes and myoblasts; suggested to be a consequence of the potential stem cell niches within dental pulp tissue [1].

Adult stem cells are proposed to exist in a hierarchical arrangement. Pivotal to this model is the mother stem cell, which divides slowly and asymmetrically to yield a replacement mother cell and rapidly dividing transit amplifying (TA) cells [8]. It has been proposed that as TA cells continue to divide, their proliferative capacity is reduced and they become more lineage-restricted. In contrast, newly formed TA cells possess a greater proliferative and multi-differentiation capacity. The presence of TA cells has been suggested to rise within the postnatal dental pulp, which are the first to differentiate into new odontoblast-like cells following cavity-induced injury [9]. Whilst this would indicate a strong role for TA cells in tissue repair and regeneration, the nature, origins or the relationship of DPSC populations with contrasting proliferative capacities to this hierarchical arrangement, have yet to be elucidated.

Another important requirement for the tissue engineering exploitation of stem cells is the considerable in vitro cell expansion required before sufficient cell numbers are obtained for therapeutic use. However, a significant limitation of stem cell therapy is that extensive in vitro cell expansion eventually leads to proliferative decline and cellular senescence, accompanied by altered cellular behaviour and impaired regenerative potential [10]. This feature has been particularly reported for the in vitro expansion of MSCs from human bone marrow, where no more than 4-7 PDs is recommended in preparations for therapeutic use [11]. For most cell types, in vitro expansion and subsequent cellular senescence is a consequence of replicative (telomere-dependent) senescence, characterised by progressive telomere shortening and the loss of telomeric TTAGGG repeats, due to repeated cell divisions [12]. Cellular senescence may also occur through DNA damage by $\mathrm{p} 53$, ionizing radiation or oxidative stress (premature or telomere-independent senescence). Either mechanism is associated with the activation of various signalling pathways, including those involving the tumour suppressor genes, p53 and retinoblastoma protein $(\mathrm{pRb})$, via the cyclin-dependant kinase inhibitors, $\mathrm{p} 21^{\text {waf1 }}$ and $\mathrm{p} 16^{\mathrm{INK4a}}$, respectively [12]. However, foetal cells, germ lines, stem cells and many tumour cells are established to contain the human telomerase catalytic subunit (hTERT); a reverse transcriptase capable of the complete replication of telomere ends, which plays a major role in counteracting erosion, maintaining telomeric integrity and proliferative lifespan in these cells [13].
Although significant differences in the ex vivo expansion capabilities of individual DPSC populations has been recognized for some time, few studies have addressed the reasons behind these differences and the subsequent impact of such variations on differentiation and regenerative potential. Consequently, this study aimed to examine whether inherent differences in telomere lengths and relative susceptibilities to cellular senescence between individual DPSC populations, contributed to the significant variations in proliferative and differentiation capabilities identified for individual DPSC populations. To achieve this, proliferative lifespans, stem cell marker expression, multi-potent differentiation capabilities and senescence-related marker development, were characterized for individual DPSC populations expanded from individual human teeth derived from young adults with a similar donor age range.

\section{Methods}

\section{DPSC isolation, culture and population doubling levels}

Human third molar teeth were collected from three young adult patients (Patients A-C, all female, age range 18-30 years), undergoing orthodontic extractions at the School of Dentistry, Cardiff University, UK. Teeth were collected with informed patient consent and ethical approval by the South East Wales Research Ethics Committee of the National Research Ethics Service (NRES), UK. The outer surface of the teeth were sterilised with $70 \%$ ethanol. Teeth were grooved in the mesial, distal and occlusal regions with a rotary bone saw; and halved. Pulps were removed, minced on a glass slide; and the cells were released from the pulpal tissues by digestion with $4 \mu \mathrm{g} / \mu \mathrm{l}$ collagenase/dispase ( $1 \mathrm{ml}$, Roche, Welwyn Garden City, UK), for $45 \mathrm{~min}$ at $37^{\circ} \mathrm{C}$. Pulpal tissues from individual patients were prepared separately. Digests were passed through a $70 \mu \mathrm{m}$ mesh cell strainer and the eluents collected to obtain single cell suspensions. Cells were centrifuged and further resuspended in $1 \mathrm{ml}$ culture medium; $\alpha$-Minimum Essential Medium ( $\alpha$ MEM) containing ribonucleosides, deoxyribonucleosides, $4 \mathrm{mM}$ L-glutamine, $100 \mathrm{U} / \mathrm{ml}$ penicillin $\mathrm{G}$ sodium, $0.1 \mu \mathrm{g} / \mathrm{ml}$ streptomycin sulphate, $0.25 \mu \mathrm{g} / \mathrm{ml}$ amphotericin; and 20\% foetal calf serum (all Invitrogen, Paisley, UK), in addition to $100 \mu \mathrm{M}$ L-ascorbate 2phosphate (Sigma-Aldrich, Poole, UK).

The present study utilised a fibronectin adhesion assay to preferentially select and isolate immature DPSCs, based on their expression of high $\beta_{1}$-integrin levels on stem cell surfaces [14]. This fibronectin adhesion isolation method has previously been used successfully for the isolation of tissue-specific, immature stem / progenitor cells from dental pulp [15, 16], oral mucosa [17], cartilage [18]; and bone marrow [16]. Briefly, viable cell counts were calculated and cells seeded onto fibronectin-coated, 6-well plates, at 4000 cells $/ \mathrm{cm}^{2}$. 
Plates were subsequently maintained at $37{ }^{\circ} \mathrm{C} / 5 \% \mathrm{CO}_{2}$ for $20 \mathrm{~min}$, in accordance with our previously published protocol $[15,16]$. Following adhesion, the culture medium and non-adherent cells were removed and replaced with $2 \mathrm{ml}$ aMEM medium. Medium was replenished every 2 days.

Colonies ( $>32$ cells) were allowed to form over 12 days in culture, with individual colonies isolated within cloning rings using $100 \mu \mathrm{l}$ pre-warmed, accutase (PAA, Velizy-Villacoublay, France); and seeded into 1 well of a 96-well plate. Isolated colonies were subsequently expanded until the numbers were sufficient for seeding into T-75 flasks. Of the DPSC colonies established from Patients A-C, six populations (A1, A2 and A3; B1; C2 and C3) were expanded, with PDs for each DPSC population calculated from cell counts throughout their proliferative lifespans in culture until reaching senescence, as previously described [19]. DPSC senescence was identified when PDs were reduced to $<0.5$ PDs / week and later confirmed by the increased presence of other senescence-related markers, as described below.

\section{Telomere length determination}

DPSCs at various PDs throughout their proliferative lifespans (A1, B1 and C2 at 8 PDs, A2 at 12 PDs, A3 at 9 PDs and 55 PDs, C3 at 16 PDs), were seeded in T-75 flasks at 5000 cells $/ \mathrm{cm}^{2}$ and grown to confluence. Genomic DNA was isolated from each DPSC population using QIAmp DNA Mini Kits (Qiagen, Crawley, UK), according to manufacturer's instructions; and DNA yields quantified at $260 \mathrm{~nm}$ (NanoVue, GE Healthcare, Amersham, UK). Telomere length assessments were performed using the TeloTAGGG Telomere Restriction Fragment Length (TRF) Assay Kit (Roche), according to manufacturer's instructions. Briefly, each DNA sample $(1 \mu \mathrm{g})$ was digested with HinF1 / Rsa1 (both $40 \mathrm{U} / \mu \mathrm{l}$, in Kit), at $37^{\circ} \mathrm{C}$ for $2 \mathrm{~h}$. DPSC samples, a digoxigenin (DIG)-labelled, Molecular Weight Marker and a positive DIG-labelled, Control DNA sample (both in Kit), were separated (20 mV, overnight) on $0.8 \%$ by agarose gels (Agarose MP, Geneflow, Lichfield, UK); in 1x Trisacetate-EDTA buffer containing $0.2 \mu \mathrm{g} / \mathrm{ml}$ ethidium bromide (Sigma-Aldrich). Gels were subsequently treated with $0.25 \mathrm{M}$ hydrochloric acid solution (Thermo Fisher Scientific) and rinsed (x2) with water, before treatment (x2) with Denaturation Solution (0.5 M sodium hydroxide, $1.5 \mathrm{M}$ sodium chloride solution), rinsing ( $\mathrm{x} 2$ ); and treatment with Neutralisation Solution (0.5 M Tris$\mathrm{HCl}$ buffer, $\mathrm{pH} 7.5$, containing $3 \mathrm{M}$ sodium chloride).

Separated products were transferred onto positively charged nylon membranes (Roche) by Southern blotting; using $20 \times$ standard sodium citrate (SSC) buffer (3 M sodium chloride / $0.3 \mathrm{M}$ sodium citrate solution, $\mathrm{pH}$ 7.0). Nylon membranes were fixed by UV-crosslinking for
$2 \times 10 \mathrm{~s}$ (Stratalinker, Agilent Technologies, Stockport, $\mathrm{UK}$ ) and washed with SSC (x2), prior to hybridisation with DIG Easy Hyb (in Kit), for $1 \mathrm{~h}$ at $42{ }^{\circ} \mathrm{C}$. This was replaced with Hybridisation Solution mixed with Telomere Probe $\left(2 \mu \mathrm{l}\right.$, in Kit); and incubated at $42{ }^{\circ} \mathrm{C}$ for $3 \mathrm{~h}$. Membranes were consecutively washed (x2) with $25 \mathrm{ml}$ Stringent Wash Buffers, before incubations in Blocking Solution, Anti-DIG-AP Working Solution, Washing Buffer (x2); and Detection Buffer, respectively (all in Kit). Finally, membranes were incubated for $5 \mathrm{~min}$ in Chemiluminescent Substrate Solution (in Kit), before being exposed (30 s) to X-ray film (Hyperfilm, GE Healthcare) and developed.

Average DPSC telomere lengths at each PD were calculated from the Southern blot images, using Imagej Software (http://rsb.info.nih.gov/ij/), to quantify the densitometic intensity profile of the entire length of the separated products within each particular lane. In line with TRF Assay Kit instructions, each lane was overlaid along its entire length with a grid consisting of 30 equal squares, where telomere-specific signal was detectable. The background intensity of each lane was calculated by selecting squares within each lane containing no telomere-specific signal and by subtracting these averaged values from the squares containing telomeric signal. For each square containing detectable telomeric signal, the total signal density within each square $\left(\mathrm{OD}_{\mathrm{i}}\right)$ and the corresponding molecular weight at the midpoint of each square $\left(\mathrm{L}_{\mathrm{i}}\right)$ (based on the DIG-labelled, Molecular Weight Marker bands, kb), were calculated. Average telomere lengths were subsequently calculated, using the following formula, where $\mathrm{OD}_{\mathrm{i}}$ is the chemiluminescent signal and $L_{i}$ is the length of the telomeres at position i:-

$$
\frac{\Sigma\left(\mathrm{OD}_{\mathrm{i}}\right)}{\sum\left(\mathrm{OD}_{\mathrm{i}} / \mathrm{L}_{\mathrm{i}}\right)}
$$

\section{Stem cell and senescence-related marker expression}

DPSCs were examined by RT-PCR for the expression of purported stem / progenitor cell markers (CD73, CD90, CD105, CD271) and the absence of the hematopoietic stem cell marker (CD45); at various PDs throughout their proliferative lifespans (1-10 PDs, 11-23 PDs, 24-60 PDs and where applicable, $>60$ PDs). In addition, DPSCs at early PDs were assessed for the expression of hTERT, whilst expression of the senescence-associated marker genes, p53, p $21^{\text {wafl }}$ and $\mathrm{p} 16^{\mathrm{INK} 4 \mathrm{a}}$, were analysed for all DPSCs at PDs throughout their proliferative lifespans. DPSCs were cultured in 6-well plates until $\sim 90 \%$ confluence. Total RNA was isolated for DPSCs using an RNeasy Mini Kit (Qiagen), according to the manufacturer's instructions. RNA was quantified by measurement of 260:280 $\mathrm{nm}$ ratio 
(NanoVue). cDNA was synthesised from $1 \mu \mathrm{g}$ total RNA, using 5x Moloney murine leukaemia virus (M-MLV) buffer, $0.5 \mu \mathrm{g}$ Random Primers, $0.625 \mu \mathrm{l}$ RNasin, $1.25 \mu \mathrm{l}$ dNTPs $(10 \mathrm{mM})$ and $1 \mu \mathrm{l} \mathrm{M-MLV}$ reverse transcriptase, reconstituted to $25 \mu \mathrm{l}$ with DNase-free water (all Promega, Southampton, UK, total volume $15 \mu \mathrm{l})$. All reactions were performed on a G-storm ${ }^{\text {tm }}$ GS1 Thermal Cycler (Genetic Research Instrumentation, Braintree, UK), at $37^{\circ} \mathrm{C}$ for $1 \mathrm{~h}$, followed by $95^{\circ} \mathrm{C}$ for $5 \mathrm{~min}$.

PCR reactions were established including CDNA $(1 \mu \mathrm{l})$, 5x Green GoTaq $^{\text {Tu }}$ Flexi Buffer $(5 \mu \mathrm{l}), 25 \mathrm{mM}$ Magnesium Chloride Solution $(1 \mu \mathrm{l}), 10 \mathrm{mM}$ PCR Nucleotide Mix $(0.5 \mu \mathrm{l}), 5 \mathrm{U} / \mu \mathrm{l} \mathrm{GoTaq}{ }^{\text {Th }}$ DNA Polymerase $(0.25 \mu \mathrm{l}$, all Promega), $0.04 \mu \mathrm{g} / \mu \mathrm{l}$ forward primer and $0.04 \mu \mathrm{g} / \mu \mathrm{l}$ reverse primer (both $1.25 \mu \mathrm{l}$ ). PCR were performed using the primer sequences and cycling conditions described in Table 1 , with $\beta$-actin serving as the reference housekeeping gene in all cases. Primer replacement with DNase-free water served as the negative controls. All reaction volumes were made up to $25 \mu \mathrm{l}$ with DNase-free water. Reactions were run on a G-storm ${ }^{\text {Tw }}$ GS1 Thermal Cycler, with an initial denaturing step of $95{ }^{\circ} \mathrm{C}(5 \mathrm{~min})$, followed by $35-40$ cycles at $95^{\circ} \mathrm{C}(1 \mathrm{~min}), 1$ cycle at $55-$ $62{ }^{\circ} \mathrm{C}(1 \mathrm{~min}), 1$ cycle at $72{ }^{\circ} \mathrm{C}(1 \mathrm{~min})$; and 1 cycle at
$72{ }^{\circ} \mathrm{C}$ (5 min). PCR products and a 100 bp DNA ladder (Promega) were separated on $2 \%$ agarose gels $(125 \mathrm{mV}$, $45 \mathrm{~min}$ ), in 1x Tris-acetate-EDTA buffer (above). Gel images were captured under UV light and analysed using a Gel Doc 3000 Scanner and Image Analysis Software (Bio-Rad, Hemel Hempstead, UK).

\section{DPSC differentiation capabilities}

Based on the distinct proliferative differences identified above between A3 and the other DPSC populations assessed, further studies compared the respective osteogenic chondrogenic and adipogenic differentiation capabilities of A3 (at 30 PDs, 62 PDs, and 75 PDs), versus low proliferative capacity DPSC populations, A1 (17 PDs) and B1 (25 PDs). Differentiation was assessed using commercially available media (OsteoDiff, ChondroDiff and AdipoDiff, Miltenyi Biotec, Bisley, UK), according to manufacturer's protocols and following supplementation with antibiotics, as above.

For the analysis of osteogenic capabilities, DPSCs were seeded at $4.5 \times 10^{3}$ cells $/ \mathrm{cm}^{2}$ in 6- or 12-well plates; and maintained in OsteoDiff medium at $37{ }^{\circ} \mathrm{C} / 5 \% \mathrm{CO}_{2}$ for 18 days. Medium was replenished every 3 days. At day 18 , cells in 6-well plates were used for the RT-PCR

Table 1 Details of the primer sequences and cycling conditions used for RT-PCR

\begin{tabular}{|c|c|c|c|c|}
\hline Gene marker & Primer sequence & Annealing temp. $\left({ }^{\circ} \mathrm{C}\right)$ & Cycles & NCBI reference sequence \\
\hline $\mathrm{CD73}$ & $\begin{array}{l}\text { F:5'GTCGCGAACTTGCGCCTGGCCGCCAAG-3' } \\
\text { R: 5'-TGCAGCGGCTGGCGTTGACGCACTTGC-3' }\end{array}$ & 65 & 35 & NM_001204813.1 \\
\hline CD90 & $\begin{array}{l}\text { F:5'- ATGAACCTGGCCATCAGCATCG-3' } \\
\text { R:5'- CACGAGGTGTTCTGAGCCAGCA-3' }\end{array}$ & 55 & 35 & NM_006288.3 \\
\hline CD105 & $\begin{array}{l}\text { F:5'-GAAACAGTCCATTGTGACCTTCAG-3' } \\
\text { R: 5'-GATGGCAGCTCTGTGGTGTTGACC-3' }\end{array}$ & 65 & 35 & NM_001114753.2 \\
\hline CD271 & $\begin{array}{l}\text { F:5'- CTGCAAGCAGAACAAGCAAG-3' } \\
\text { R:5'- GGCCTCATGGGTAAAGGAGT-3' }\end{array}$ & 55 & 35 & NM_002507.3 \\
\hline CD45 & $\begin{array}{l}\text { F:5'-GTGACCCCTTACCTACTCACACCACTG-3' } \\
\text { R:5'-TAAGGTAGGCATCTGAGGTGTTCGCTG-3' }\end{array}$ & 65 & 35 & NM_002838.4 \\
\hline hTERT & $\begin{array}{l}\text { F:5'- CGGAAGAGTGTCTGGAGCAA-3' } \\
\text { R:5'- GGATGAAGCGGAGTCTGGA-3' }\end{array}$ & 55 & 40 & NM_198253.2 \\
\hline p53 & $\begin{array}{l}\text { F:5'- AGACCGGCGCACAGAGGAAG-3' } \\
\text { R:5'- CTIITGGACTTCAGGTGGC-3' }\end{array}$ & 55 & 35 & NM_001126118.1 \\
\hline $\mathrm{p} 21^{\text {waf } 1}$ & $\begin{array}{l}\text { F:5'- GGATGTCCGTCAGAACCCAT-3' } \\
\text { R:5'- CCCTCCAGTGGTGTCTCGGTG-3' }\end{array}$ & 60 & 35 & NM_001291549.1 \\
\hline $\mathrm{p} 16^{\mathrm{INK} 4 \mathrm{~A}}$ & $\begin{array}{l}\text { F:5'- CTTCCTGGACACGCTGGT-3' } \\
\text { R:5'- GCATGGTACTGCCTCTGGT-3' }\end{array}$ & 55 & 35 & NM_001195132.1 \\
\hline OCN & $\begin{array}{l}\text { F:5'-GCAGGTGCGAAGCCCAGCGGTGCAGAG-3' } \\
\text { R: 5'-GGGCTGGGAGGTCAGGGCAAGGGCAAG-3' }\end{array}$ & 62 & 35 & NM_199173.4 \\
\hline OPN & $\begin{array}{l}\text { F:5'- ATCACCTGTGCCATACCA-3' } \\
\text { R:5'- CATCTTCATCATCCATATCATCCA-3' }\end{array}$ & 55 & 35 & NM_001251830.1 \\
\hline PPARY & $\begin{array}{l}\text { F:5'-GCCATCAGGTTGGGGCGGATGCCACAG-3' } \\
\text { R: 5'-CCTGCACAGCCTCCACGGAGCGAAACT-3' }\end{array}$ & 62 & 35 & NM_138711.3 \\
\hline LPL & $\begin{array}{l}\text { F:5'-GCTGGCATTGCAGGAAGTCTGACCAATAA-3' } \\
\text { R:5'-GGCCACGGTGCCATACAGAGAAATCTCAA-3' }\end{array}$ & 55 & 35 & NM_000237.2 \\
\hline$\beta$-actin & $\begin{array}{l}\text { F:5'-AGGGCAGTGATCTCCTTCTGCATCCT-3' } \\
\text { R:5'- CCACACTGTGCCCATCTACGAGGGGT-3' }\end{array}$ & 65 & 35 & NM_001101.3 \\
\hline
\end{tabular}


analysis of Runx2, osteocalcin (OCN) and osteopontin (OPN) expression (Table 1), whilst the 12-well plates were washed $(\mathrm{x} 2)$ with phosphate buffered saline (PBS) and fixed with $4 \%$ paraformaldehyde (Santa Cruz, Dallas, USA) for $10 \mathrm{~min}$ and washed with PBS (x2). Osteogenic cultures were assessed for mineral nodule deposition detection by staining with $2 \%$ alizarin red solution, $\mathrm{pH} 4.2$ (500 $\mu \mathrm{l} / \mathrm{well}$, Sigma-Aldrich), for $3 \mathrm{~min}$. Images representing the extent of alizarin red staining were captured by light microscopy (Eclipse TS100, Nikon UK, Kingston upon Thames, UK), using a digital camera (Canon PC1234, Uxbridge, UK).

Chondrogenic capacity was analysed using single cell suspensions containing $2.5 \times 10^{5}$ DPSCs in $1 \mathrm{ml}$ medium, which were centrifuged to produce cell pellets. Medium was replaced with $1 \mathrm{ml}$ of ChondroDiff medium, prior to re-centrifugation. Pellets were maintained in ChondroDiff medium at $37{ }^{\circ} \mathrm{C} / 5 \% \mathrm{CO}_{2}$ for 24 days. Medium was replenished every 3 days. At day 24, pellets were washed ( $\mathrm{x} 1$ ) with PBS, prior to fixation overnight in 3.7\% neutral buffered formalin. Each pellet underwent automated histological processing (Leica ASP300 S, Leica Microsystem, Milton Keynes, UK), through a graded alcohol series and paraffin wax embedding. Sections $(5 \mu \mathrm{m})$ were cut using a sliding microtome (Leica SM2400, Leica Microsystems), collected onto poly-L-lysine coated slides (SuperFrost, Thermo Fisher Scientific); and dried. Sections were deparaffinised and rehydrate with xylene $(10 \mathrm{~min})$, industrial methylated spirits $(5 \mathrm{~min})$ and water $(5 \mathrm{~min})$. Pellet sections were treated with fast green FCF solution (1:5000, Sigma-Aldrich) for $5 \mathrm{~min}$ and washed in $1 \%$ acetic acid (Thermo Fisher Scientific). Sections were assessed for proteoglycan content by $0.1 \%$ Safranin O staining (Sigma-Aldrich) for $10 \mathrm{~min}$; and washed in $95 \%$ ethanol-xylene mixture (1:1). Images representing the extent of Safranin O staining were captured, as above.

For the analysis of adipogenic capabilities, DPSCs were seeded at $7.5 \times 10^{3}$ cells $/ \mathrm{cm}^{2}$ in 6 - or 12 -well plates; and maintained in AdipoDiff medium at $37{ }^{\circ} \mathrm{C} / 5 \% \mathrm{CO}_{2}$ for 21 days. Medium was replenished every 3 days. At day 21, cells in 6-well plates were used for the RT-PCR analysis of adipogenic marker, lipoprotein lipase (LPL) and PPAR $\gamma$ expression (Table 1), whilst the 12-well plates were washed (x2) with PBS and assessed for intracellular lipidrich vacuole accumulation by Oil Red O staining (500 $\mu \mathrm{l} /$ well, Sigma-Aldrich; $3.5 \mathrm{~g} / \mathrm{l}$ in isopropanol, mixed 3:2 with double-distilled water), for $10 \mathrm{~min}$. Following excess stain removal with double-distilled water and $60 \%$ isopropanol, images representing the extent of Oil Red O staining were captured, as above.

\section{DPSC morphology and size assessment}

Digital images were captured, as above, to assess changes in cellular size and morphology throughout each DPSC's proliferative lifespan. Random cells ( 20 cells / image, 3 images / PD) were outlined along their peripheral borders and cellular surface areas calculated, using Imagej Software. Surface areas were expressed as an average \pm standard error of the mean (SE) for each DPSC population and PD.

\section{Senescence-associated $\beta$-galactosidase staining}

DPSCs at defined PDs throughout their proliferative lifespans were seeded into 6 -well plates at 5000 cells $/ \mathrm{cm}^{2}$ and maintained at $37{ }^{\circ} \mathrm{C} / 5 \% \mathrm{CO}_{2}$ for $24 \mathrm{~h}$. A Senescence Cell Histochemical Kit (Sigma-Aldrich) was used to detect senescence-associated $\beta$-galactosidase activity in these cells, according to manufacturer's instructions. Culture medium was aspirated and the cells washed (x2) with PBS (in Kit). DPSCs were treated with Fixation Buffer $(1.5 \mathrm{ml} /$ well, in Kit) for $7 \mathrm{~min}$ and washed $(\mathrm{x} 3)$ with PBS (1 ml / well). Cells were further treated with Staining Solution $\left(1 \mathrm{ml} /\right.$ well, in Kit) and incubated at $37{ }^{\circ} \mathrm{C}$ / $5 \% \mathrm{CO}_{2}$, overnight. Digital images representing the extent of senescence-associated $\beta$-galactosidase staining were captured by light microscopy, as above. Random cells (100 cells in total) were counted and the percentage number of positive $\beta$-galactosidase stained cells calculated.

\section{Statistical analysis}

Statistical analysis on the differences in cellular surface area (average \pm SE) between DPSC populations throughout their proliferative lifespans, was determined by oneway ANOVA with post-test Tukey multiple comparison analysis, using GraphPad InStat 3 (GraphPad Software, La Jolla, USA). Statistical significance were considered at $p<0.05$.

\section{Results}

DPSC isolation, expansion and population doubling levels Following the isolation of immature DPSC populations using the fibronectin adherence selection methodology $[15,16]$, DPSCs were allowed to form colonies of $>32$ cells over a 12 day period. Of the DPSC colonies established, a selection of six populations (A1, A2 and A3; B1; $\mathrm{C} 2$ and $\mathrm{C} 3$ ), were subsequently expanded in vitro through to senescence, confirmed when cumulative PDs fell to $<0.5$ PDs/week. The cumulative PDs for each DPSC population are presented in Fig. 1a. Marked variations in proliferative capacity were evident between individual DPSC populations, with each demonstrating differences in PDs, irrespective of whether DPSCs were derived from the same or different patients. This was particularly apparent with A3, which demonstrated the highest PD levels (>80 PDs) over 280 days in culture, whilst other DPSC populations from the same patient (A1 and A2) and different patients (B1, C2 and C3) only achieved between 20 and 35 PDs over 35-85 days in 
(A)

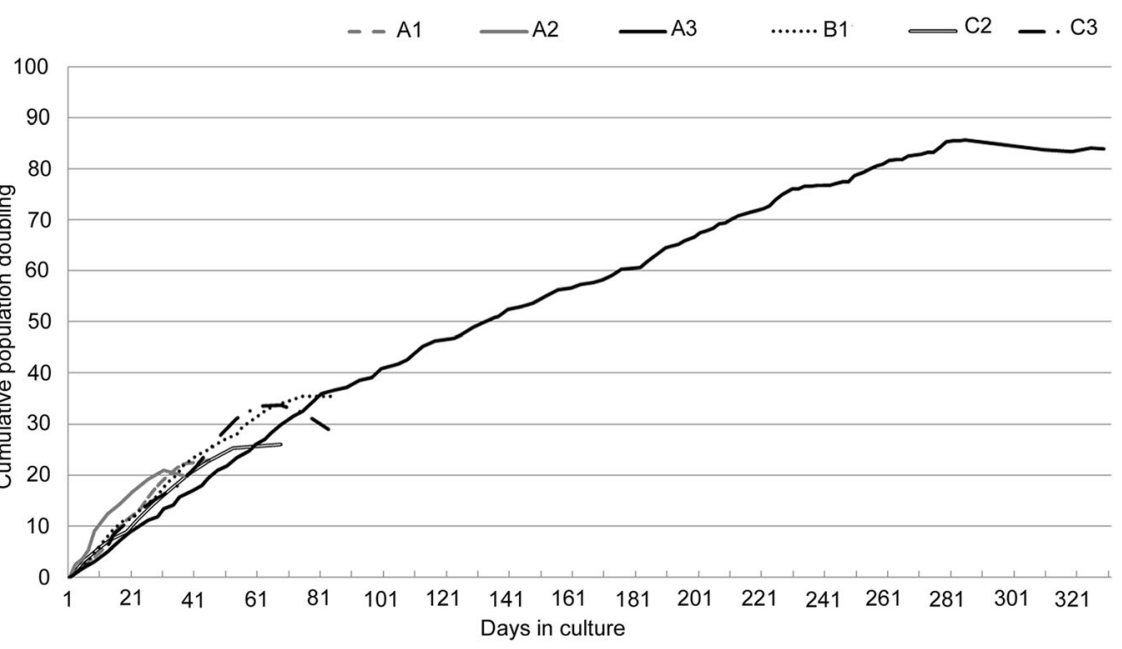

(B)

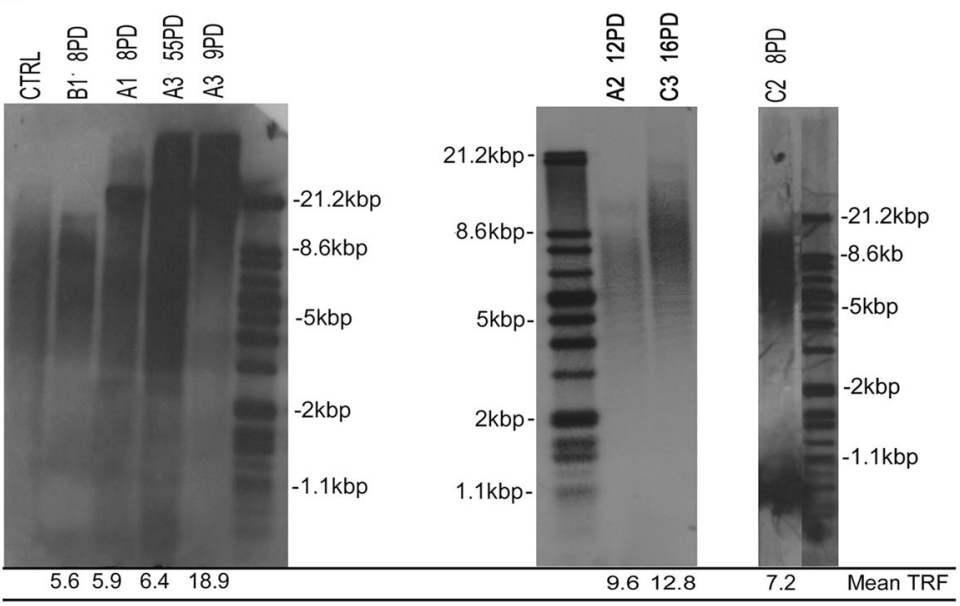

(C)

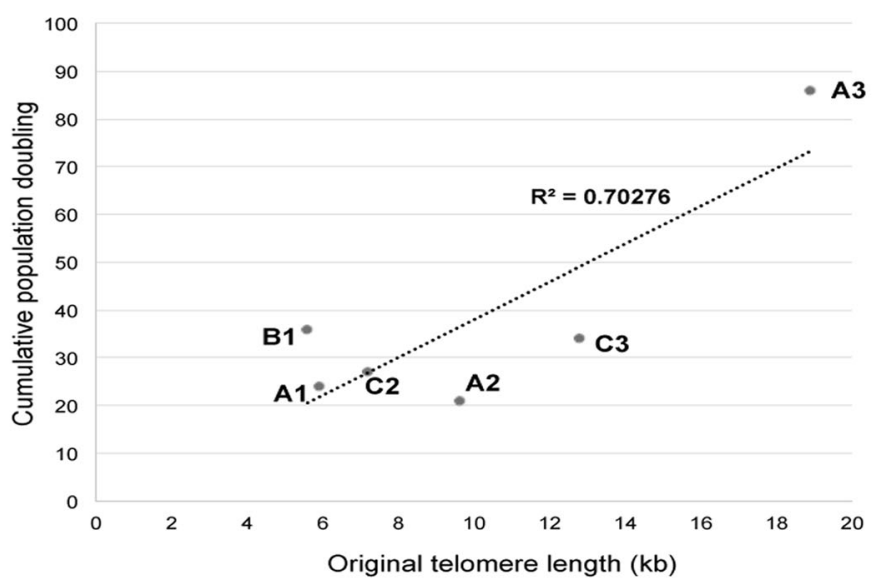

Fig. 1 (See legend on next page.) 
(See figure on previous page.)

Fig. 1 Characterisation of DPSC populations derived from human dental pulp tissues. a Cumulative population doublings (PDs) were recorded for six DPSC populations during extended culture until senescence was reached, when PDs reached $<0.5$ PDs / week. DPSCs A1, A2 and A3 were derived from patient A, while B1, C2 and C3 were derived from patients B and C, respectively. Population A3 demonstrated high proliferative capacity, achieving $>80$ PDs over 280 days in culture, whilst the other DPSC populations only achieved 20-35 PDs over 35-85 days in culture. $\mathbf{b}$ Telomere length analysis for the six DPSC populations at cited PDs, by Southern blotting. Average telomere lengths were calculated using Image $J^{\circ}$ Software. Much longer telomeres were identified with high proliferative capacity, A3 (18.9 kb), compared with low proliferative capacity populations, A1 (5.9 kb), A2 (9.6 kb), B1 (5.6 kb), C2 (7.2 kb) and C3 (12.8 kb). A3 (18.9 kb, 9 PDs) only exhibited equivalent telomere lengths to low proliferative capacity DPSCs, at much later PDs towards the end of its proliferative lifespan ( $6.4 \mathrm{~kb}, 55 \mathrm{PDs})$. CTRL lanes represent the separate DIG-labelled, Control DNA sample. Average telomere lengths values obtained for each CTRL lane from left-right, were $10.6 \pm 0.73 \mathrm{~kb}, 11.4 \pm$ $0.71 \mathrm{~kb}$ and $11.1 \pm 0.60 \mathrm{~kb}$, respectively. Separated DIG-labelled telomere length standards are also included. c Correlation between cumulative PDs versus original telomere lengths for all DPSCs analysed

culture. In support of the contrasting PDs capabilities between these DPSC populations, telomere length analysis demonstrated much longer average telomere lengths with high proliferative capacity, A3 (18.9 kb), compared with DPSCs with low proliferative capacities at comparable PDs, A1 (5.9 kb), A2 (9.6 kb), B1 (5.6 kb), C2 (7.2 kb) and C3 (12.8 kb) (Fig. $1 \mathrm{~b}$ and c). The consistency of analysis between separate Southern blots was confirmed by the average telomere lengths calculated for each positive Control DNA sample on each blot (i.e. $10.6 \pm 0.73 \mathrm{~kb}, 11.4 \pm 0.71 \mathrm{~kb}$ and $11.1 \pm 0.60 \mathrm{~kb}$, for the CTRL lanes from left-right in Fig. 1b, respectively).

\section{Stem cell and senescence-related marker expression}

Each DPSC population was further investigated to compare stem/progenitor cell marker expression at early PDs (Fig. 2). All DPSCs demonstrated the expression of the MSC markers (CD73, CD90 and CD105) and the absence of the hematopoietic marker, CD45 [3]. Low proliferative capacity DPSCs (A1, A2, B1, C2 and C3) were also positive for the expression of nerve growth factor receptor p75 (CD271). All DPSCs analysed also demonstrated the expression of the senescence-associated marker genes, $\mathrm{p} 21^{\text {waf1 }}$ and $\mathrm{p} 16^{\mathrm{INK} 4 \mathrm{a}}$, at early PDs; although $\mathrm{p} 16^{\mathrm{INK} 4 \mathrm{a}}$ expression appeared to be much less for the high proliferative capacity, A3, than with the low proliferative capacity DPSCs (A1, A2, B1, C2 and C3). Similarly, the other senescence-associated marker investigated, p53, was only expressed in the low proliferative capacity DPSCs (A1, A2, B1, C2 and C3); being undetectable in high proliferative capacity, A3. All DPSCs analysed were negative for hTERT expression.

\section{DPSC differentiation capabilities}

Based on the contrasting PDs identified between A3 and the other DPSCs assessed, further studies evaluated whether these populations also possessed contrasting differentiation capabilities. Tri-lineage (osteogenic, chondrogenic and adipogenic) differentiation was compared between high proliferative capacity, A3 (30 PDs), versus two low proliferative capacity DPSCs (A1 at 11 PDs, B1 at 15 PDs). Only high proliferative capacity, A3, demonstrated multi-potency. Osteogenic differentiation was demonstrated by positive staining with alizarin red and the up-regulation of OCN and OPN after 18 days in osteogenic medium (Fig. 3a). Chondrogenic differentiation was evident by positive Safranin $\mathrm{O}$ staining for high proteoglycan content, following 24 days in chondrogenic medium (Fig. 3b). However, mRNA extraction from cartilage pellets was difficult and thus, prevented gene expression analysis. A3 was also able to undergo adipogenic differentiation, evident by the presence of Oil Red O-positive, lipid vacuoles and the up-regulation of the late adipogenic marker, LPL, expression after 21 days

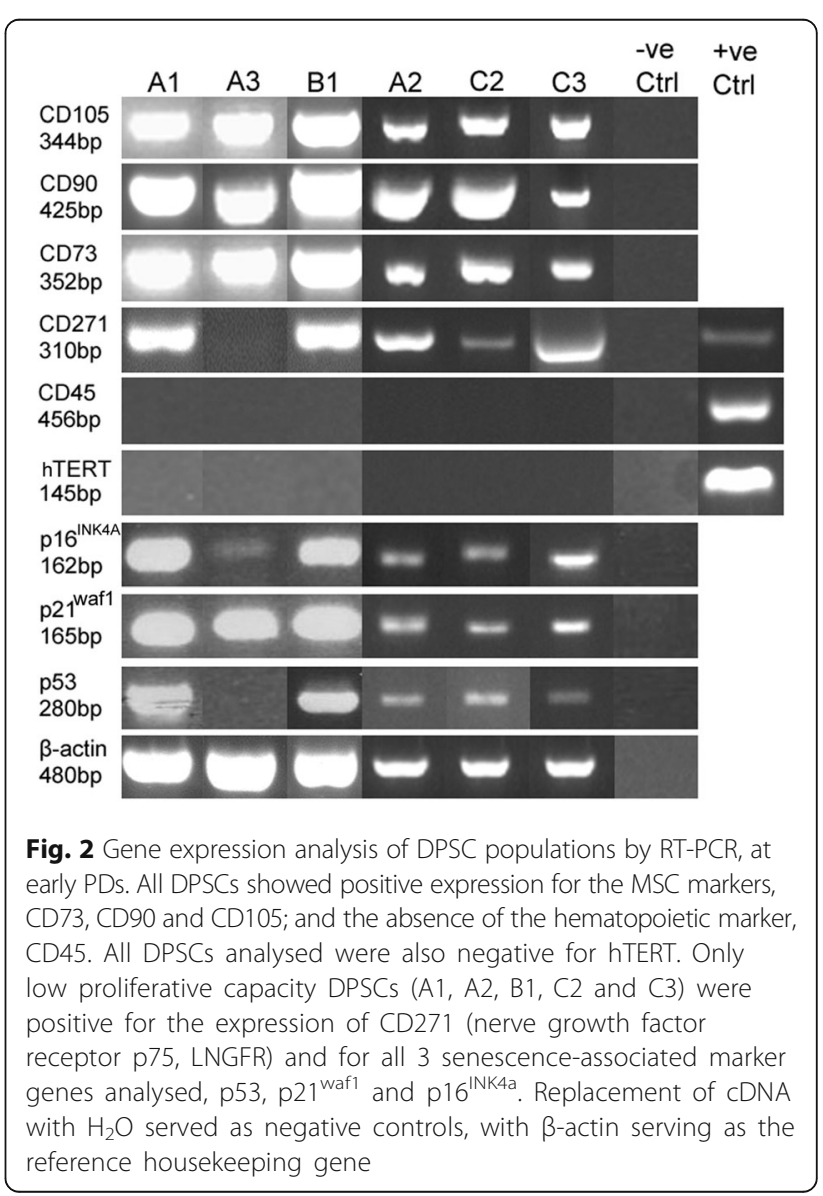


(A)

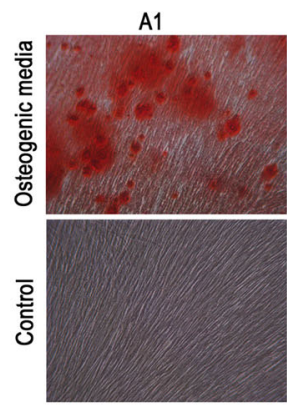

(B)

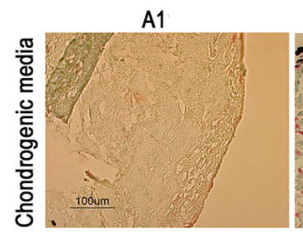

(C)
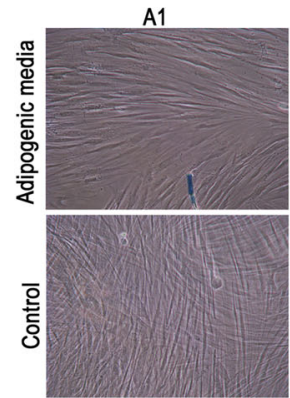
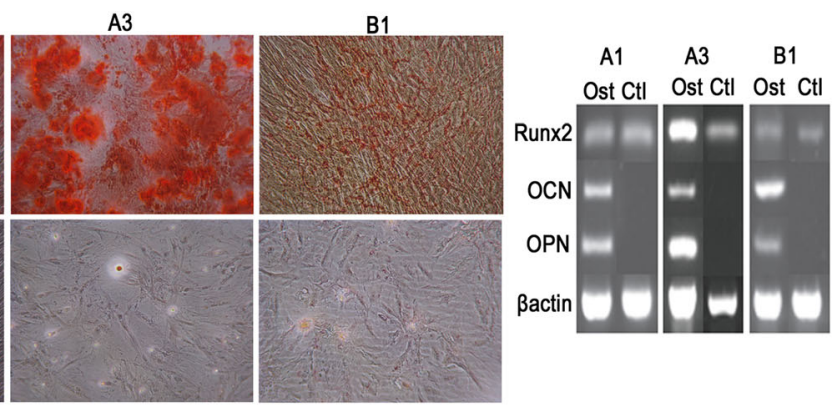

B1

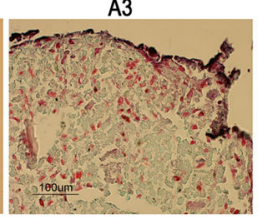

A3
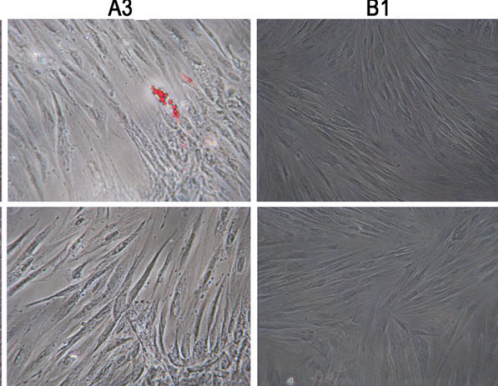

Fig. 3 Osteogenic, chondrogenic and adipogenic differentiation of DPSCs. Tri-lineage differentiation analysis was compared between high proliferative capacity, A3 (30 PDs) and low proliferative capacity DPSCs, A1 (11 PDs) and B1 (15 PDs). a Osteogenesis was confirmed for each DPSC population by the detection of alizarin red staining for mineralised calcium nodules. No staining was observed in control DPSC cultures in the absence of osteogenic medium. RT-PCR analysis of osteogenic markers (right panel) indicated increased osteocalcin (OCN) and osteopontin (OPN) expression for DPSCs cultured in osteogenic media. Cells maintained in both osteogenic and control media expressed Runx2. $\mathbf{b}$ Chondrogenesis was only particularly evident with high proliferative capacity, A3, which exhibited positive Safranin O staining for high proteoglycan content. No Safranin O staining was observed with the low proliferative capacity DPSCs, A1 and B1. c Adipogenesis was only particularly evident with high proliferative capacity, A3, which exhibited positive Oil Red O staining for intracellular lipid-rich vacuole accumulation. No Oil Red O staining was observed with the low proliferative capacity DPSCS, A1 and B1; or in control cultures in the absence of adipogenic medium. RT-PCR analysis of adipogenic markers (right panel) indicated increased expression of the early adipogenic marker, PPARY, in all DPSCs maintained in both adipogenic and control cultures; whilst the late adipogenic marker, lipoprotein lipase (LPL), was only expressed in high proliferative capacity, A3, in adipogenic media. Scale bars $=100 \mu \mathrm{m}$. $\beta$-actin served as the reference housekeeping gene

in adipogenic medium (Fig. 3c). In contrast, low proliferative capacity DPSCs, A1 and B1, were uni-potent for osteogenic differentiation only and to a lesser extent than high proliferative capacity, A3; as confirmed by alizarin red staining and OCN / OPN expression (Fig. 3a). Of note, all three DPSCs expressed the early osteogenic and adipogenic markers, Runx2 and PPAR $\gamma$, irrespective of differentiation status (Fig. 3a and c).

\section{Prolonged in vitro expansion effects on DPSCs}

A decline in cellular proliferative capacity is wellestablished to correlate with the onset of cellular senescence; and the increased presence of characteristics associated with cellular ageing. At early (7-8 PDs), all DPSCs were morphologically similar, with the characteristic long, spindle, bipolar shape; and were negative for senescenceassociated $\beta$-galactosidase staining (Fig. 4a). Conversely, at PDs towards the later stages of their respective proliferative lifespans (examples shown for A1 at 23 PDs, A3 at 83 PDs and B1 at 34 PDs), higher percentages of cells stained positive for $\beta$-galactosidase and were larger and more stellate-like in appearance, with prominent stress fibres (Fig. 4a). This was confirmed by cell surface area measurements (Fig. 4b), which demonstrated significant increases in the surface areas of DPSCs, A1 and A3, with proliferative lifespan (for A1, approximately 6 -fold between 4 PDs and 15 PDs, 12-fold between 4 PDs and 22 PDs; for A3, approximately 6-fold between 3 PDs and 21 PDs; and 12fold between 3 PDs and 85 PDs; all $p<0.001$ ). However, only when high proliferative capacity, A3, had reached 


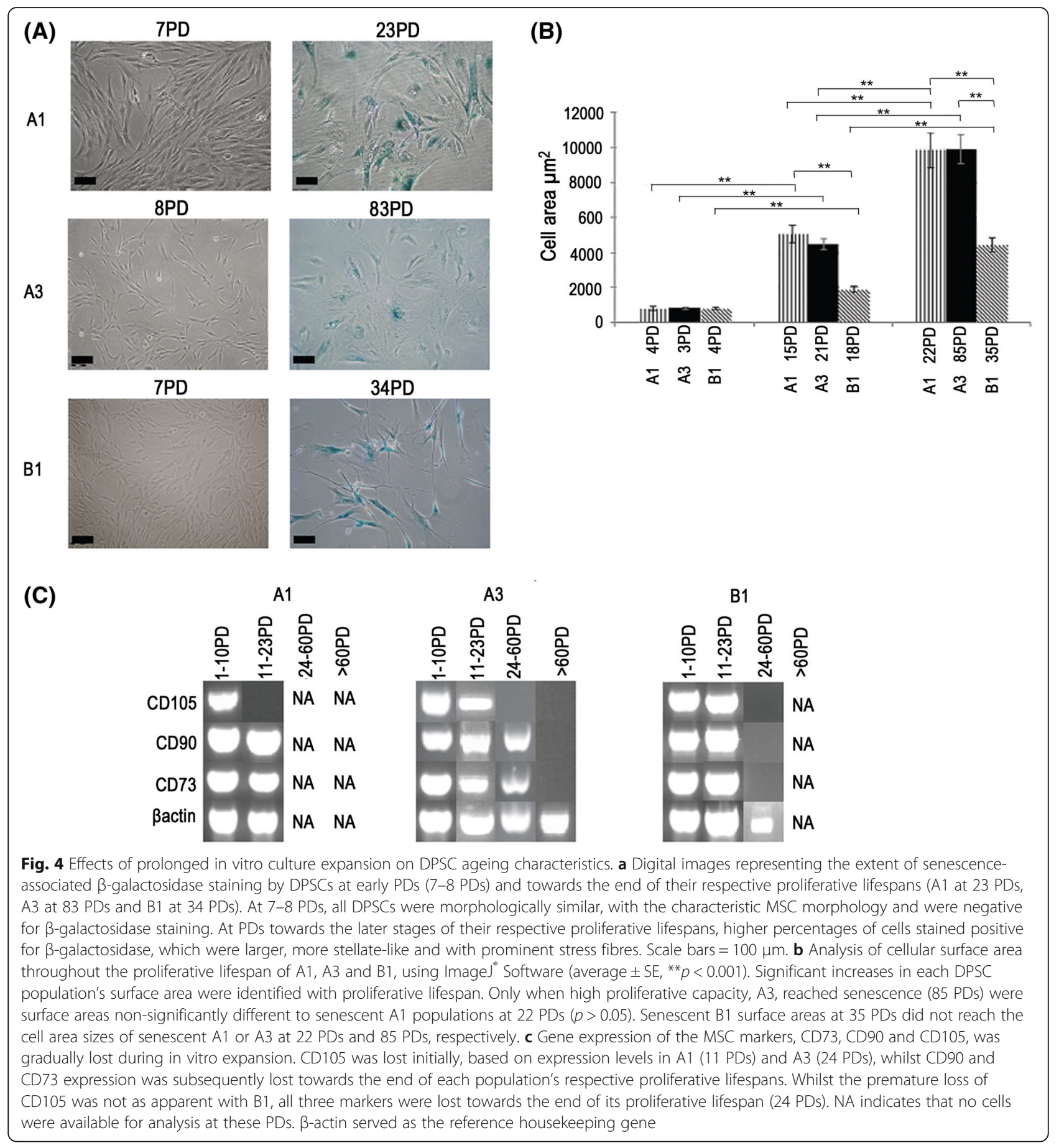

senescence at 85 PDs did it exhibit similar non-significant, cell surface area values to senescent low proliferative capacity, A1 populations, at 22 PDs $(p>0.05)$. B1 also demonstrated similar trends of increasing cell surface area with proliferative lifespan, with significant increases in the surface areas with proliferative lifespan (approximately 2.5fold between 4 PDs and 18 PDs; and 5-fold between 4 PDs and 35 PDs (both $p<0.001$ ). However, senescent B1 surface areas at 35 PDs did not reach the cell area sizes of senescent A1 or A3 at 22 PDs and 85 PDs, respectively.

Although the stem/progenitor cell markers, CD73, CD90 and CD105, were previously shown to be expressed by DPSCs, A1, A3 and B1, at early PDs, the expression of these markers was gradually lost during in vitro expansion (Fig. 4c). CD105 appeared to be lost initially, based on expression levels in A1 (11 PDs) and A3 
(24 PDs). CD90 and CD73 expression was subsequently lost from these DPSC populations towards the end of their respective proliferative lifespans. Whilst the premature loss of CD105 was not apparent with B1, all three markers were lost towards the end of its proliferative lifespan.

\section{Prolonged in vitro expansion effects on DPSC differentiation}

In light of the superior proliferative capacity and multipotent differentiation properties of the A3 population at early PDs, we also determined whether these preferential differentiation capabilities were diminished with prolonged in vitro expansion, in line with those of low proliferative capacity DPSCs, A1 and B1. A3 telomere lengths decreased from $18.9 \mathrm{~kb}$ (9 PD) to $6.4 \mathrm{~kb}$ (55 PD) (Fig. 1b). In line with such decreases in telomere length, the osteogenic potential of A3 was greatly reduced following culture expansion from 30 PDs to 62 PDs and 75 PDs, apparent by a reduction in alizarin red staining and the loss of osteogenic marker, Runx2, OCN and OPN, expression (Fig. 5a). However, subsequent analyses indicated that the clear loss of A3 osteogenic differentiation potential at 75 PDs, was concomitant with the increased presence of enlarged intracellular lipid vesicles (Oil Red O staining) and the increased expression of early and late adipogenic markers, PPAR $y$ and LPL (Fig. 5b).

\section{Discussion}

Similar to other tissue sources such as bone marrow, MSC populations in dental pulp are recognised to be heterogeneous populations, with isolated DPSCs demonstrating differences in proliferative rates and ability to differentiate along various lineages. The present study was successful in isolating DPSCs from adult human dental pulp tissues, in order to characterize the relative expansion potentials of individual DPSC populations through to cellular senescence; and the impact of these proliferative lifespan differences on stem/progenitor cell characteristics and multi-potent differentiation potential. Although many animal and human studies have established the effects of increasing donor chronological age on the impairment of stem/progenitor cell regenerative capabilities [20-24], to our knowledge, this is the first study to report inherent differences in the telomere lengths of individual DPSC populations from within a young donor age group (18-30 years); and their correlations to the distinct differentiation capabilities of each population. Indeed, despite DPSCs from young adults with similar donor age ranges having previously been reported to exhibit no significant differences in proliferative or differentiation potential $[23,25]$, this study identified differences between high (A3) and low (A1 and A2) proliferative capacity DPSC populations, even from the same pulpal tissue sample.

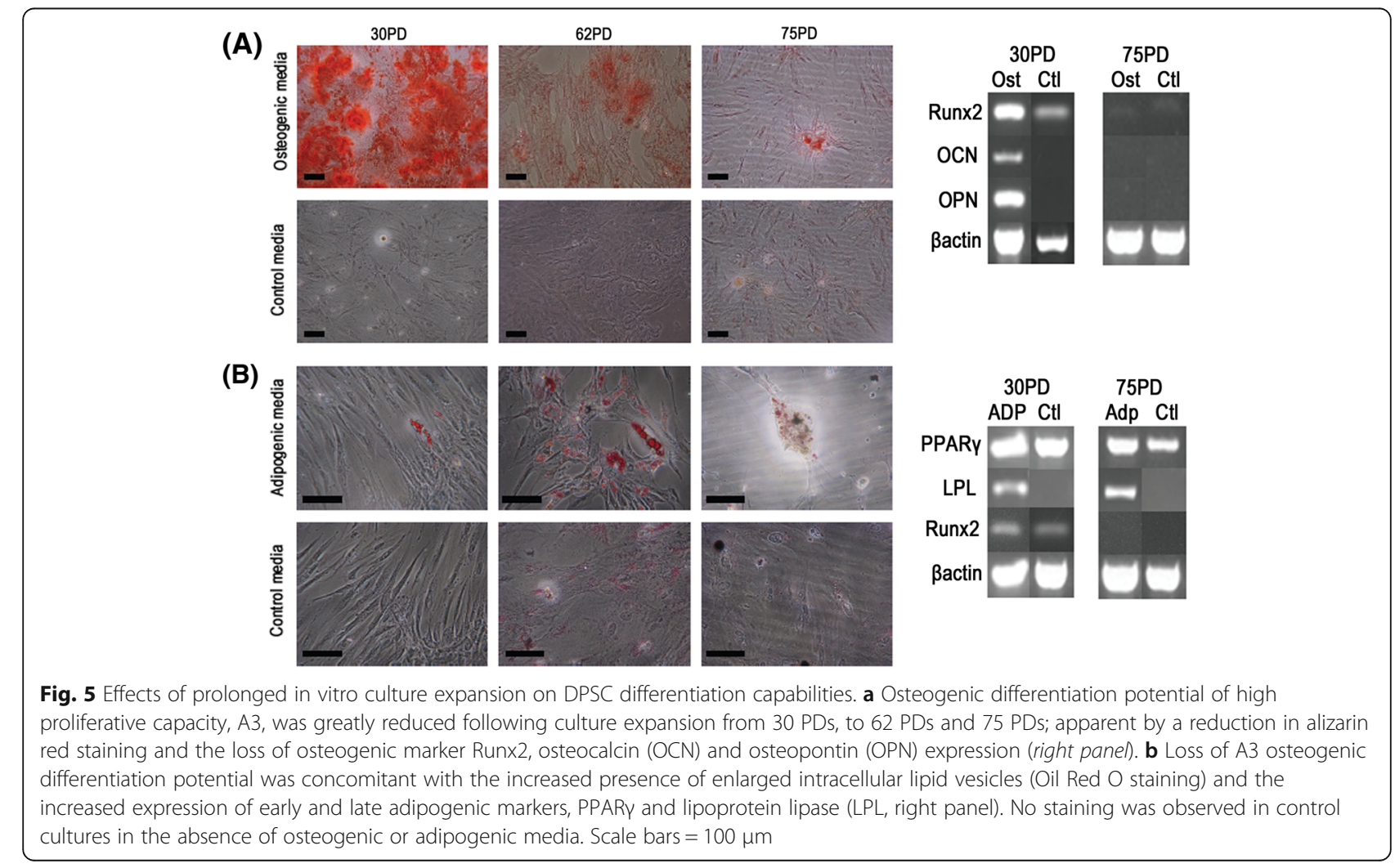


DPSC population, A3, possessed an extensive proliferative capacity ( $>80 \mathrm{PDs}$ ), which was $2-4 \times$ the proliferative lifespans of other DPSC populations expanded (2035 PDs). In support of these findings, A3 was further shown to be morphologically smaller, possessed fewer senescence-associated $\beta$-galactosidase positive cells and lacked the expression of p53 and p16 ${ }^{\mathrm{INK} 4 \mathrm{a}}$, at PDs where low proliferative capacity DPSCs (A1, A2, B1, C2 and C3) demonstrated increased detection of these senescence-associated markers. Such conclusions are consistent with only $20 \%$ of purified DPSCs being able to proliferate beyond 20 PDs, whilst it can be surmised that high proliferative capacity DPSCs, such as A3, are responsible for the extensive expansion potential of heterogeneous DPSC populations (>120 PDs) in vitro [5, 7], as DPSCs with less proliferative potential are selectively lost from the mixed population during extended subculture $[15,16]$. A consequence of A3 possessing a superior proliferative lifespan was the retention of stem cell characteristics, evident by the maintenance of marker expression (CD73, CD90 and CD105) for longer periods in culture ( $\geq 23 \mathrm{PDs}$ ), compared to the other DPSCs analysed. A3 was also the only population capable of multi-potent osteogenic, chondrogenic and adipogenic differentiation, at least up to 30 PDs in culture. In contrast, other DPSCs appeared lineage-restricted to osteogenic differentiation only. Therefore, there appears to be a clear association between DPSC PDs and the relative differentiation abilities of these populations. However, as DPSCs derived from adult teeth are generally regarded to possess lower proliferation rates and longer population doubling times than those isolated from human exfoliated deciduous teeth (SHEDs) [2629], it is conceivable that SHEDs are still likely to have equivalent or even greater proliferative potential than adult DPSCs.

The principle reason identified to be behind these contrasting proliferative responses were the average telomere lengths of the DPSC populations. Although it is possible that these differences reflect the relative number of cell divisions undertaken by each stem cell before isolation, such contrasting telomere lengths may also suggest the existence of sub-populations of DPSCs within the stem cell population, with superior telomere dynamic characteristics. Indeed, at early PDs, A3 (18.9 kb) demonstrated telomere lengths $1.5-3.5 \times$ longer than low proliferative DPSCs $(\sim 5-13 \mathrm{~kb})$. A3 only exhibited equivalent telomere lengths to those of the low proliferative DPSCs at much later PDs towards the end of its proliferative lifespan (6.4 kb, $55 \mathrm{PDs})$, corresponding to the increased presence of senescence-associated markers. Actively proliferating stem cells are well-known to possess longer telomeres (10-20 kb), compared to somatic cells $(5-15 \mathrm{~kb})$ [30], whilst previous studies have reported DPSC telomere lengths between 9.4 and $12.1 \mathrm{~kb}$ [31]. Therefore, the contrasting telomere lengths determined for high and low proliferative capacity DPSCs are generally in line with those previously identified in MSCs from other sources.

Based on the correlation comparison between cumulative PDs versus original telomere lengths for all DPSCs analysed, it appears that this relationship is a little more complex than expected, particularly between the low proliferative capacity DPSCs (A1, A2, B1, C2 and C3). For instance, $\mathrm{C} 3(12.8 \mathrm{~kb})$ had an initial telomere length $2-3 \times$ longer than A1 (5.9 kb) and B1 (5.6 kb), yet exhibited similar proliferative capacities (20-35 PDs). The extrinsic and intrinsic factors which influence the respective telomere lengths and PD capabilities of individual DPSC populations remain to be elucidated, although inherent differences due to inter-patient donor variation are likely to play a significant role. As this initial proof-of-concept study has only compared 6 separate DPSC populations (5 low proliferative and 1 high proliferative) from 3 separate donors, we acknowledge that the present study is somewhat limited, particularly in terms of number of highly proliferative DPSCs with longer telomeres assessed. Consequently, further research is warranted with much larger numbers of high and low proliferative DPSCs from different donors, in order to fully establish the relationship between telomere lengths and how these impact on the overall PD capabilities and multi-potent differentiation capabilities of individual DPSC populations.

Although certain studies have reported hTERT expression in human DPSCs [31, 32], we and others have shown that human DPSCs possess no or negligible hTERT expression [33-35]. Therefore, it appears that hTERT may not be wholly responsible for maintaining telomere lengths in high proliferative capacity DPSCs or for the significant variations in DPSC proliferative capabilities, implying that other intrinsic telomere protective mechanisms exist [36, 37]. Nonetheless, the later onset of senescence in A3 was supported by the delayed expression of senescence-associated genes, most notably p53 and p16 ${ }^{\mathrm{INK} 4 \mathrm{a}}$, at PDs where these and the other senescence marker gene (p21 $\left.{ }^{\text {wafl }}\right)$ assessed, were highly expressed in low proliferative capacity DPSCs. MSC replicative senescence is acknowledged to be a multistep process driven by p53, which promotes growth arrest by inducing p21 wafl expression, thereby inhibiting $G_{1}-S$ phase progression [12]. MSC telomere erosion can also initiate $\mathrm{pRb} / \mathrm{p} 16^{\mathrm{INK} 4 \mathrm{a}}$ checkpoints, triggering permanent senescent states by preventing pRB phosphorylation and suppressing cell proliferation. Alternatively, senescence mediators, such as $\mathrm{p} 53, \mathrm{p} 16^{\mathrm{INK} 4 \mathrm{a}}$ and $\mathrm{pRb}$, are also associated with premature/telomere-independent senescence [12]. The proliferative, telomere length reductions and senescence-related marker detection with increasing 
proliferative lifespan presented herein, firmly suggest that the senescence of high proliferative capacity DPSCs, such as A3, is a consequence of replicative senescence; although it is plausible that both $\mathrm{G}_{1}-\mathrm{S}$ phase inhibition and $\mathrm{pRb} /$ p16 ${ }^{\text {INK4a }}$ checkpoint initiation contribute to A3 senescence [12]. In contrast, as p53 and $\mathrm{p} 16^{\mathrm{INK} 4 \mathrm{a}}$ are also implicated in the onset of premature senescence, we can only speculate at present which is the principle mechanism of early senescence and the reasons underlying the pre-existing shortened telomeres in low proliferative capacity DPSCs, following their isolation and short-term in vitro expansion. Nonetheless, as p53 and p $16^{\mathrm{INK} 4 \mathrm{a}}$ have both been demonstrated to be the principal mediators of senescence in MSCs $[23,34,38,39]$, as p21 ${ }^{\text {wafl }}$ also has a role in maintaining stem cell renewal due to its positive effects on cell cycle progression [40]; the contrasting p53 and p16 ${ }^{\mathrm{INK} K \mathrm{a}}$ expression between high (A3) and low (A1, A2, B1, C2 and C3) proliferative capacity DPSCs further confirms the earlier onset of senescence with less proliferative populations at early PDs, compared to A3.

Although telomere length maintenance is recognized to facilitate cell division in stem cell populations [41], a notable observation within this study was the impact that contrasting telomere dynamics between high and low proliferative capacity DPSCs has on lineage differentiation capabilities. Whilst A3 exhibited multi-potency towards osteogenic, chondrogenic and adipogenic lineages at early PDs, low proliferative capacity DPSCs, such as A1 and B1, were only uni-potent for osteogenesis. Only following extensive culture expansion beyond 30 PDs did the osteogenic potential of $\mathrm{A} 3$ decline, with a corresponding increase in adipogenic differentiation. Such findings concur with previous reports of reduced multi-potency in DPSCs and MSCs from other sources, with extensive proliferative expansion and senescence [23, 34, 42, 43]. Evidence indicates that osteogenesis and adipogenesis are inversely regulated by transcription factors, Runx 2 and PPAR $\gamma$, with changes to cellular osteogenic/adipogenic potential with age being a consequence of transcription factor dysregulation $[41,43]$.

Another key consideration relating to the findings, is whether the contrasting regenerative properties between high and low proliferative capacity DPSC populations reflect their isolation from different mesodermal or neuroectodermal origins $[44,45]$, stem cell niches within the dental pulp [2], or are from the same origin, but are at different stages within the proposed hierarchical model for adult stem cells [8]. Although the nature and origins of these DPSCs within dental pulpal tissues have yet to be fully elucidated, the absence of cell surface marker, CD271 (nerve growth factor receptor p75, LNGFR), expression in high proliferative capacity and multi-potent DPSCs, such as A3, may suggest that such populations are not neural crest- or sub-odontoblast layer-derived, as
$\mathrm{CD} 271^{+}$cells are regarded as being of neural crest origin and have been located within the cell-rich, subodontoblast region of dental pulp [44, 46]. In line with the uni-potentiality of low proliferative capacity DPSCs, CD271 has been proposed to inhibit DPSC adipogenic, chondrogenic, myogenic and osteogenic potential [47, 48], although not all studies have demonstrated complete inhibition of multi-potent differentiation in CD271-expressing DPSCs [44, 45]. Nonetheless, positive CD271 expression in low proliferative capacity DPSCs (A1, A2, B1, C2 and C3), may provide further credence to these cells being more lineage restricted than high proliferative capacity DPSCs, such as A3.

The prominence of low proliferative capacity and less potent DPSC populations in the present study may imply that high proliferative capacity/multi-potent DPSCs with longer telomere and lacking CD271 expression represent a minor population within the heterogeneous DPSCs in dental pulp tissues; meaning that highly proliferative/long telomere DPSC populations are more difficult to identify and isolate from pulpal tissues, although donor variability is also likely to contribute to this. However, the identification of telomere length and CD271 expression differences between high and low proliferative capacity and multi-/unipotent DPSCs does advocate their use as potential phenotypic biomarkers for the identification and selective isolation of superior proliferative capacity DPSC populations from dental pulp tissues for regenerative medicine purposes. Variations in telomere lengths have previously been used as selective markers for the isolation of particular stem/progenitor cell populations from tissues, such as bone marrow and cartilage $[49,50]$. Furthermore, CD271 has recently been identified to be highly expressed in STRO- $1^{+} / \mathrm{c}-\mathrm{Kit}^{+} / \mathrm{CD} 34^{+}$DPSC populations, possessing slow proliferation rates, reduced stemness and early-onset senescence; compared to their STRO $-1^{+} / \mathrm{c}-\mathrm{Kit}^{+} / \mathrm{CD} 34^{-}$ counterparts [45]. However, despite differences in CD271 expression, both DPSC sub-populations exhibited similar osteogenic, myogenic and adipogenic differentiation, although STRO- $1^{+} / \mathrm{c}-\mathrm{Kit}^{+} / \mathrm{CD} 34^{+}$DPSCs expressing CD271 demonstrated greater neurogenic lineage commitment. High $\mathrm{CD}^{+} 0^{+}$expressing DPSCs with low CD271 expression have also been demonstrated to possess superior colony-forming efficiencies, prolonged in vitro proliferative/multi-lineage potential; and enhanced in vivo bone formation capabilities, versus CD90 ${ }^{+}$CD271 ${ }^{+}$DPSCs [48].

\section{Conclusions}

This study has reiterated the significant variability in the proliferative and differentiation capabilities for individual DPSC populations expanded from individual human teeth from donors within a similar age range; and even identified inherent differences between DPSC populations derived from the same patient. The findings 
presented also strongly support the use of telomere length and CD271 expression as viable markers of high proliferative capacity and multi-potent DPSC populations. Consequently, if such superior DPSC populations are to be fully exploited for regenerative medicine, we must utilise these and other potential markers of DPSC proliferation and senescence, such as Bmi-1 and SSEA-4 $[34,51]$. Such criteria will allow the optimization of population selection by selectively screening and isolating better quality DPSCs from whole dental pulp tissues for in vitro expansion and assessment, aiding the translational development of more effective DPSC-based therapies for clinical evaluation and application.

\section{Abbreviations \\ DPSCs: Dental pulp stem cells; hTERT: Human telomerase catalytic subunit; LBL: Lipoprotein lipase; M-MLV: Moloney murine leukaemia virus; MSC: Mesenchymal stem cell; NRES: National Research Ethics Service; OCN: Osteocalcin; OPN: Osteopontin; PBS: Phosphate buffered saline; PDs: Population doublings; PPARY: Peroxisome proliferator-activated receptor $\gamma$; pRb: Retinoblastoma protein; RT-PCR: Reverse transcription polymerase chain reaction; SSC: Sodium citrate; TA: Transit amplifying; TRF: Telomere restriction fragment length; aMEM: a-minimum essential medium}

\section{Acknowledgements}

The authors acknowledge for the receipt of PhD studentship funding for $\mathrm{Dr}$ Amr Alraies to undertake this study, from Albawani Company, Saudi Arabia. This study was funded by a PhD studentship, provided by Albawani Company, Saudi Arabia.

\section{Availability of data and materials}

Data are available in Figshare website through the following links: https://figshare.com/articles/Figure_1/3160420 https://figshare.com/articles/Figure_2/3160444 https://figshare.com/articles/Figure_3/3160450 https://figshare.com/articles/Figure_4/3160417

https://figshare.com/articles/Figure_5/3160453

\section{Authors' contributions \\ AA: Performed most of the experimental work, participated in study design and preparation of the final manuscript. NA: Performed the remainder of the experimental work not undertaken by AA. RW: Advisor to the study and participated in the preparation of the final manuscript. RM: Project Supervisor, participated in study design and preparation of the final manuscript. AS: Project Supervisor, participated in study design and preparation of the final manuscript. All authors read and approved the final manuscript.}

\section{Competing interest}

The authors declare that they have no competing interests.

\section{Ethics approval and consent}

All human teeth were collected with informed patient consent and ethical approval by the South East Wales Research Ethics Committee of the National Research Ethics Service (NRES) (permission number: 07/WESE04/84).

\begin{abstract}
Author details
${ }^{1}$ Mineralised Tissue Group, Oral and Biomedical Sciences, School of Dentistry, College of Biomedical and Life Sciences, Cardiff University, Heath Park, CF14 $4 X Y$, Cardiff, UK. ${ }^{2}$ Cardiff Institute Tissue Engineering and Repair (CITER), Cardiff University, Cardiff CF14 4XY, UK. ${ }^{3}$ Stem Cells, Wound Repair and Regeneration, Oral and Biomedical Sciences, School of Dentistry, College of Biomedical and Life Sciences, Cardiff University, Heath Park, Cardiff CF14 4XY,
\end{abstract} UK.

Received: 9 July 2016 Accepted: 20 January 2017

Published online: 02 February 2017

\section{References}

1. Huang GT, Gronthos S, Shi S. Mesenchymal stem cells derived from dental tissues vs. those from other sources: Their biology and role in regenerative medicine. J Dent Res. 2009;88(9):792-806.

2. Sloan AJ, Waddington RJ. Dental pulp stem cells: What, where, how? Int J Paediatr Dent. 2009:19(1):61-70.

3. Kawashima N. Characterisation of dental pulp stem cells: A new horizon for tissue regeneration? Arch Oral Biol. 2012:57(11):1439-58.

4. Tatullo M, Marrelli M, Shakesheff KM, White LJ. Dental pulp stem cells: function, isolation and applications in regenerative medicine. J Tissue Eng Regen Med. 2015;9(11):1205-16.

5. Gronthos S, Brahim J, Li W, Fisher LW, Cherman N, Boyde A, et al. Stem cell properties of human dental pulp stem cells. J Dent Res. 2002;81(8):531-5.

6. Shi S, Gronthos S. Perivascular niche of postnatal mesenchymal stem cells in human bone marrow and dental pulp. J Bone Miner Res. 2003:18(4):696-704.

7. Gronthos S, Mankani M, Brahim J, Robey PG, Shi S. Postnatal human dental pulp stem cells (DPSCs) in vitro and in vivo. Proc Natl Acad Sci U S A. 2000; 97(25):13625-30

8. Stocum DL. Developmental mechanisms of regeneration. In: Atala A, Lanza $R$, Thomson JA, Nerem RA, editors. Foundations of regenerative medicine. San Diego: Academic; 2010. p. 100-25.

9. Téclès O, Laurent P, Zygouritsas S, Burger AS, Camps J, Dejou J, About I. Activation of human dental pulp progenitor/stem cells in response to odontoblast injury. Arch Oral Biol. 2005;50(2):103-8.

10. Wagner $W$, Ho AD, Zenke $M$. Different facets of aging in human mesenchymal stem cells. Tissue Eng Part B Rev. 2010;16(4):445-53.

11. Banfi A, Muraglia A, Dozin B, Mastrogiacomo M, Cancedda R, Quarto R. Proliferation kinetics and differentiation potential of ex vivo expanded human bone marrow stromal cells: Implications for their use in cell therapy. Exp Haematol. 2000;28(6):707-15.

12. Campisi J, d'Adda di Fagagna F. Cellular senescence: When bad things happen to good cells. Nat Rev Mol Cell Biol. 2007:8(9):729-40.

13. Serakinci N, Graakjaer J, Kolvraa S. Telomere stability and telomerase in mesenchymal stem cells. Biochimie. 2008;90(1):33-40.

14. Jones PH, Watt FM. Separation of human epidermal stem cells from transit amplifying cells on the basis of differences in integrin function and expression. Cell. 1993;73(4):713-24.

15. Waddington RJ, Youde SJ, Lee CP. Sloan AJ. Isolation of distinct progenitor stem cell populations from dental pulp. Cells Tissues Organs. 2009;189(1-4):268-74.

16. Harrington J, Sloan AJ, Waddington RJ. Quantification of clonal heterogeneity of mesenchymal progenitor cells in dental pulp and bone marrow. Connect Tissue Res. 2014;55 Suppl 1:62-7.

17. Davies LC, Locke M, Webb RD, Roberts JT, Langley M, Thomas DW, et al. A multipotent neural crest-derived progenitor cell population is resident within the oral mucosa lamina propria. Stem Cells Dev. 2010;19(6):819-30

18. Dowthwaite GP, Bishop JC, Redman SN, Khan IM, Rooney P, Evans DJ, et al. The surface of articular cartilage contains a progenitor cell population. J Cell Sci. 2004:117(6):889-97.

19. Cristofalo VJ, Allen RG, Pignolo RJ, Martin BG, Beck JC. Relationship between donor age and the replicative lifespan of human cells in culture: A reevaluation. Proc Natl Acad Sci U S A. 1998;95(18):10614-9.

20. Ma D, Ma Z, Zhang X, Wang W, Yang Z, Zhang M, et al. Effect of age and extrinsic microenvironment on the proliferation and osteogenic differentiation of rat dental pulp stem cells in vitro. J Endo. 2009:35(11):1546-53.

21. Bressan E, Ferroni L, Gardin C, Pinton P, Stellini E, Botticelli D, et al. Donor age-related biological properties of human dental pulp stem cells change in nanostructured scaffolds. PLoS One. 2012;7(11):e49146.

22. Feng $X$, Xing J, Feng $G$, Sang A, Shen B, Xu Y, et al. Age-dependent impaired neurogenic differentiation capacity of dental stem cell is associated with Wnt/ $\beta$-catenin signalling. Cell Mol Neurobiol. 2013;33(8):1023-31.

23. Feng $X$, Xing J, Feng G, Huang D, Lu X, Liu S, et al. p16 ${ }^{\text {INK4A }}$ mediates agerelated changes in mesenchymal stem cells derived from human dental pulp through the DNA damage and stress response. Mech Ageing Dev. 2014;141-142C:46-55.

24. Horibe H, Murakami M, Iohara K, Hayashi Y, Takeuchi N, Takei $Y$, et al. Isolation of a stable subpopulation of mobilized dental pulp stem cells (MDPSCs) with high proliferation, migration and regeneration potential is independent of age. PLoS One. 2014;9(5):e98553.

25. Kellner M, Steindorff MM, Strempel JF, Winkel A, Kühnel MP, Stiesch M. Differences of isolated dental stem cells dependent on donor age and 
consequences for autologous tooth replacement. Arch Oral Biol. 2014; 59(6):559-67.

26. Nakamura S, Yamada Y, Katagiri W, Sugito T, Ito K, Ueda M. Stem cell proliferation pathways comparison between human exfoliated deciduous teeth and dental pulp stem cells by gene expression profile from promising dental pulp. J Endod. 2009;35(11):1536-42

27. Lee S, An S, Kang TH, Kim KH, Chang NH, Kang S, Kwak CK, Park HS. Comparison of mesenchymal-like stem/progenitor cells derived from supernumerary teeth with stem cells from human exfoliated deciduous teeth. Regen Med. 2011;6(6):689-99.

28. Wang X, Sha XJ, Li GH, Yang FS, Ji K, Wen LY, Liu SY, Chen L, Ding Y, Xuan K. Comparative characterization of stem cells from human exfoliated deciduous teeth and dental pulp stem cells. Arch Oral Biol. 2012;57(9):1231-40.

29. Abdullah MF, Abdullah SF, Omar NS, Mahmood Z, Fazliah Mohd Noor SN, Kannan TP. Mokhtar Kl. Proliferation rate of stem cells derived from human dental pulp and identification of differentially expressed genes. Cell Biol Int. 2014;38(5):582-90.

30. Cheng PH, Snyder B, Fillos D, Ibegbu CC, Huang AH, Chan AW. Postnatal stem/progenitor cells derived from the dental pulp of adult chimpanzee. BMC Cell Biol. 2008;9:20-30.

31. Jeon BG, Kang EJ, Kumar BM, Maeng GH, Ock SA, Kwack DO, et al. Comparative analysis of telomere length, telomerase and reverse transcriptase activity in human dental stem cells. Cell Transplant. 2011; 20(11-12):1693-705

32. Hakki SS, Kayis SA, Hakki EE, Bozkurt SB, Duruksu G, Unal ZS, et al. Comparison of mesenchymal stem cells isolated from pulp and periodontal ligament. J Periodontol. 2015;86(2):283-91.

33. Egbuniwe O, Idowu BD, Funes JM, Grant AD, Renton T, Di Silvio L. P16/p53 expression and telomerase activity in immortalized human dental pulp cells. Cell Cycle. 2011;10(22):3912-9.

34. Mehrazarin S, Oh JE, Chung CL, Chen W, Kim RH, Shi S, et al. Impaired odontogenic differentiation of senescent dental mesenchymal stem cells is associated with loss of Bmi-1 expression. J Endod. 2011;37(5):662-6.

35. Murakami M, Horibe H, lohara K, Hayashi Y, Osako Y, Takei Y, et al. The use of granulocyte-colony stimulating factor induced mobilization for isolation of dental pulp stem cells with high regenerative potential. Biomaterials. 2013;34(36):9036-47.

36. Liu J, Cao L, Finkel T. Oxidants, metabolism and stem cell biology. Free Radic Biol Med. 2011;51(12):2158-62.

37. Shyh-Chang N, Daley GQ, Cantley LC. Stem cell metabolism in tissue development and aging. Development. 2013;140(12):2535-47.

38. Shibata KR, Aoyama T, Shima Y, Fukiage K, Otsuka S, Furu M, et al. Expression of the $p 16^{\text {INK4A }}$ gene is associated closely with senescence of human mesenchymal stem cells and is potentially silenced by DNA methylation during in vitro expansion. Stem Cells. 2007;25(9):2371-82.

39. Muthna D, Soukup T, Vavrova J, Mokry J, Cmielova J, Visek B, et al. Irradiation of adult human dental pulp stem cells provokes activation of p53, cell cycle arrest, and senescence but not apoptosis. Stem Cells Dev. 2010;19(12):1855-62.

40. Ju Z, Choudhury AR, Rudolph KL. A dual role of p21 in stem cell aging. Ann N Y Acad Sci. 2007;1100:333-44.

41. Allen ND, Baird DM. Telomere length maintenance in stem cell populations. Biochim Biophys Acta. 2009;1792(4):324-8

42. Cheng H, Qiu L, Ma J, Zhang H, Cheng M, Li W, et al. Replicative senescence of human bone marrow and umbilical cord derived mesenchymal stem cells and their differentiation to adipocytes and osteoblasts. Mol Biol Rep. 2011;38(8):5161-8

43. Kim M, Kim C, Choi YS, Kim M, Park C, Suh Y. Age-related alterations in mesenchymal stem cells related to shift in differentiation from osteogenic to adipogenic potential: Implication to age-associated bone diseases and defects. Mech Ageing Dev. 2012;133(5):215-25.

44. Alvarez R, Lee HL, Hong C, Wang CY. Single CD271 marker isolates mesenchymal stem cells from human dental pulp. Int J Oral Sci. 2015;18(7):205-12.

45. Pisciotta A, Carnevale G, Meloni S, Riccio M, De Biasi S, Gibellini L, et al. Human dental pulp stem cells (hDPSCs): isolation, enrichment and comparative differentiation of two sub-populations. BMC Dev Biol. 2015;15:14.

46. Martens W, Wolfs E, Struys T, Politis C, Bronckaers A, Lambrichts I. Expression pattern of basal markers in human dental pulp stem cells and tissue. Cells Tissues Organs. 2012;96(6):490-500.

47. Mikami Y, Ishii Y, Watanabe N, Shirakawa T, Suzuki S, Irie S, et al. CD271/ p $75^{\mathrm{NTR}}$ inhibits the differentiation of mesenchymal stem cells into osteogenic, adipogenic, chondrogenic and myogenic lineages. Stem Cells Dev. 2011;20(5):901-13.

48. Yasui T, Mabuchi Y, Toriumi H, Ebine T, Niibe K, Houlihan DD, et al. Purified human dental pulp stem cells promote osteogenic regeneration. J Dent Res. 2016;95(2):206-14.

49. Williams R, Khan IM, Richardson K, Nelson L, McCarthy HE, Analbelsi T, et al. Identification and clonal characterisation of a progenitor cell sub-population in normal human articular cartilage. PLoS One. 2010;5:e13246.

50. Samsonraj RM, Raghunath M, Hui JH, Ling L, Nurcombe V, Cool SM. Telomere length analysis of human mesenchymal stem cells by quantitative PCR. Gene. 2013;519(2):348-55.

51. Kawanabe N, Murata S, Fukushima H, Ishihara Y, Yanagita T, Yanagita E, et al. Stage-specific embryonic antigen-4 identifies human dental pulp stem cells. Exp Cell Res. 2012;318(5):453-63.

\section{Submit your next manuscript to BioMed Central and we will help you at every step:}

- We accept pre-submission inquiries

- Our selector tool helps you to find the most relevant journal

- We provide round the clock customer support

- Convenient online submission

- Thorough peer review

- Inclusion in PubMed and all major indexing services

- Maximum visibility for your research

Submit your manuscript at www.biomedcentral.com/submit
Biomed Central 